GU J Sci, Part C, 7(1): 165-174 (2019)

Gazi Üniversitesi
Fen Bilimleri Dergisi
PART C: TASARIM VE TEKNOLOJI
http://dergipark.gov.tr/gujsc

\title{
Lojik Devre Laboratuvarları için Entegre Test Devresi Tasarımı
}

\author{
Salim ÇINAR ${ }^{1, *}$ \\ ${ }^{1}$ Niğde Ömer Halisdemir Üniversitesi, Mühendislik Fakültesi, Elektrik-Elektronik Mühendisliği Bölümü, 51240, Merkez/Nï̆ĞDE
}

\begin{abstract}
Öz
Makale Bilgisi

Başvuru: 30/07/2018

Düzeltme: 04/11/2018

Kabul: 13/01/2019

Anahtar Kelimeler

Tasarim

Entegre test devresi

Lojik devre laboratuvarı Elektrik-Elektronik Mühendisliği bölümü için önemli laboratuvarlardan bir tanesidir. Entegreler deneyler sırasında doğru bir şekilde çalışmalıdır. Entegre devrelerin düzgün çalışıp çalışmadığını test etmek için bir devre kurmak zor ve zaman alıcıdır. Bu çalışmada, entegre test cihazı entegre devrelerin hızlı ve doğru bir şekilde test edilmesi için tasarlanmıştır. Entegre test cihazında, Microchip tarafından üretilen PIC18F452 mikrodenetleyicisi kontrol ve test algoritmalarının gerçeklenmesi için kullanılmıştır. PIC18F452 düşük güç tüketimine, yüksek performansa ve geliştirilmiş FLASH/EEPROM teknolojisine sahiptir. Entegre test cihazını kullanmak kolay ve basittir. Entegreleri zif-sokete takmak yeterlidir. Test devresi, entegrelerin düzgün çalışıp çalışmadığını LCD ekranda göstermektedir. Entegre test cihazının prototipi üretilerek Lojik devre laboratuvarında kullanılmıştır. Laboratuvar personelinin deneme ve yorumları, entegre test devresinin laboratuvarlarda güvenle kullanılabileceğini göstermektedir.
\end{abstract}

Mikrodenetleyici

PIC18F452

Keywords

Design

Integrated circuits tester

Microcontroller

PIC18F452

\section{Integrated Circuits Tester Design for Logic Circuit Laboratories}

\begin{abstract}
Logic circuit laboratory is one of the important laboratories for Electrical-Electronics Engineering department. The Integrated Circuits (ICs) must work correctly during the experiments. It is difficult and time-consuming to set up a circuit to test whether the ICs are working correctly or not. In this work, the ICs tester was designed to test the ICs quickly and correctly. In the ICs tester, the PIC18F452 microcontroller produced by Microchip was used to perform the control and test algorithms. The PIC18F452 has low power consumption, high performance and improved FLASH/EEPROM technology. Using ICs tester is easy and simple. It is enough to just insert ICs into the zif-socket. The tester shows on the LCD screen whether the ICs are working correctly or not. The prototype of the ICs tester was produced and used in the logic circuit laboratory. Experiments and comments from laboratory personnel show that the ICs tester can be used safely in laboratories.
\end{abstract}

\section{GİRIŞ (INTRODUCTION)}

Mühendislik eğitimi teori ve pratik uygulamaların yoğun bir şekilde harmanlandığı zorlu bir süreçtir. İyi bir mühendis analitik düşünme ve problemi eldeki imkânları kullanarak optimum șekilde çözme becerisine sahip olmalıdır [1]. Bu problemler ihtiyaç duyulan yeni bir ürün veya mevcut sistemin değişen koşullara göre yeniden tasarlanması veya iyileştirmesi olabilir. Problemlerin çözümü için en büyük araç bilgidir. Günümüz teknolojisi sayesinde bilginin elde edilmesi kolaylaşmıştır. Fakat bu bilgi yoğunluğunun yanlış kullanılması problemlerin çözümünden çok olayların karmaşıklaşmasına sebep olabilmektedir. Mühendislik eğitiminde bilginin elde edilmesi, güvenirliğinin test edilmesi, hangi bilginin nerede ve nasıl kullanılacağı öğretilmektedir [2].

Teorik olarak öğrenilen bilgilerin gerçek problemlerde uygulanması oldukça önemlidir. Bunun için mühendislikte laboratuvar, deney ve saha çalışmalarının titizlikle yapılması gereklidir [3], [4]. Mühendisliğin bir bölümü olan Elektrik-Elektronik Mühendisliğinde (EEM) öğrenciler temel ve seçmeli laboratuvar derslerini almaktadırlar. Ölçme, lojik, devre teorisi ve elektronik laboratuvarları temel laboratuvarlara örnek olarak verilebilir. $\mathrm{Bu}$ isimler üniversitelere göre değişiklik gösterebilir ve tüm 
öğrencilerin alması zorunludur. Laboratuvar ve saha çalışmalarında kullanılacak malzemelerin ve cihazların standartlara uygunluğu yapılan deneylerin başarısını etkilemektedir. Deneylerden önce malzeme ve cihazların kontrol edilerek öğrencilere verilmesi deneylerden doğru sonuç alınmasını sağlamaktadır. Temel laboratuvarlarda öğrencilerin malzemeleri tanıması ve bağlantıların nasıl gerçekleştirileceğinin öğrenilmesi için genelde ayrık elemanlar kullanılmaktadır. Örneğin transistör, direnç, kapasitör veya lojik entegreler deney çalışmasına göre verilmektedir. Öğrenci sayısının fazla olduğu durumlarda bu malzemelerin deneylerin öncesinde ve sonrasındaki sağlamlık kontrolü önemli bir problem olarak karşımıza çıkmaktadır. Özellikle lojik devre laboratuvarında kullanılan entegrelerin sağlamlık testi zaman alan bir işlemdir. Lojik entegrelerin bacak sayısı fazladır. Temel lojik fonksiyonları yerine getiren entegreler 14 veya 16 bacaklı olabilmektedir. Lojik entegrelerin sağlamlık testi için gerekli giriş-çıkış bağlantıları yapılmalı ve ölçülen değerlerin doğruluk tablosuna göre uygunluğu kontrol edilmelidir. Bu işlemlerin el ile deney seti üzerinde yapılması zaman kaybına ve iş yükünün artmasına sebep olmaktadır. Test işlemin yapan bir devre düzeneğinin olması kontrollerin düzgün ve hızlı yapılmasına imkân sağlayacaktır.

Yapılan bu çalışmada lojik devre laboratuvarlarında kullanılmak üzere mikrodenetleyici tabanlı [5] entegre test devresi tasarlanmıştır. Devre üzerindeki zif-sokete takılan entegre mikrodenetleyici vasıtasıyla test edilir. Eğer entegre sağlam ise LCD ekran üzerinde entegrenin ismi gösterilmektedir. Çalışma belirtilen kısımlardan oluşmaktadır. Giriş bölümünde çalışmanın amacı ve gerekliliği belirtilmiştir. İkinci bölümde kullanılan yöntemler ve tasarımlardan (donanım ve yazılım) bahsedilmiştir. Üçüncü bölümde ise tasarlanan devrenin gerçek zamanlı uygulamasına yer verilmiştir. Sonuç kısmında ise elde edilen denemelerin yorumları verilmiştir.

\section{MATERYAL ve YÖNTEMLER (MATERIALS and METHODS)}

Bu bölümde çalışmada kullanılan donanım, yazılım ve tasarım aşamalarından bahsedilmiştir. Entegre test devresi iki ana kısımdan oluşmaktadır. Birinci kısım entegrelerin test edileceği donanım yapısıdır. İkinci kısım ise bu donanımı çalıştıracak yazılımın oluşturulmasıdır.

\subsection{Entegre test devresi donanım tasarımı}

Sayısal fonksiyonların gerçekleştirilmesi için lojik kapılar ve lojik elemanlar sıklıkla kullanılmaktadır. Lojik entegreler genelde plastik veya epoksi kılıflarla kaplanarak son kullanıcıya ulaşmaktadır. Lojik kapı içiren örnek bir entegrenin şematik gösterimi ve doğruluk tablosu Şekil 1'de verilmiştir. Entegre incelendiğinde A ve B gösterimi girişleri, C ise çıkışı ifade etmektedir. VCC besleme gerilimini, GND toprak hattı bağlantısını göstermektedir. Lojik fonksiyonlar incelenirken ikilik sayı sistemi kullanılır. İkilik sayı sisteminde " 0 " ve " 1 " olmak üzere iki değer vardır. Lojik elemanlarda "lojik 0" fiziksel olarak ilgili bağlantıda (giriş veya çıkış) akım veya gerilimin olmadığını, "lojik 1" ise ilgili bağlantıda akım veya gerilimin var olduğunu göstermektedir. Şekil 1'de verilen AND (VE) kapısı iki girişe bir çıkışa sahiptir ve entegre içinde bu yapıdan 4 adet mevcuttur. AND kapısı her iki girişin lojik 1 olduğu durumda çıkışında lojik 1 değeri göstermektedir. Diğer durumlarda ise çıkış lojik 0 olmaktadır. AND kapı entegresinin doğruluğunu kontrol etmek için ilk olarak uygun besleme gerilimi uygulanmalıdır. Daha sonra A ve B pinlerine giriş değerleri verilerek $C$ pininden çıkış değeri okunmalıdır. Verilen girişlere karşılık okunan çıkışlar doğruluk tablosunu sağlıyorsa ilgili entegrenin sağlam olduğu kanısına varılır.

Diğer lojik entegreler incelendiğinde giriş/çıkış, VCC ve GND pinlerinin yerleri farklı olabilmektedir. Doğruluk tablosunun sağlanması için belirtilen pinlerin uygun şekilde bağlanması gerekmektedir. $\mathrm{Bu}$ işlemlerin elde yapılması zor ve zaman alan bir süreçtir.

Yapılan çalışmada entegrelerin giriş/çıkış bağlantılarının gerçekleştirilmesi ve hızlı bir şekilde doğruluk tablosunun kontrol edilmesi için mikrodenetleyici kullanılmıştır. Mikroişlemciler temel olarak Merkezi İşlem Birimi (CPU), Veri-Kontrol-Adres Yolları (BUS) ve Giriş/Çıkış Pinlerinden oluşmaktadır. Mikroişlemciler genellikle bilgisayar sistemlerinde kullanılmaktadır. Mikrodenetleyiciler endüstride sıklıkla kullanılan gömülü sistem elemanlarıdır. Mikroişlemcilerden farkı içerisinde dâhili Rastgele Erişimli Bellek (RAM), Sadece Okunabilen Bellek (ROM), Giriş/Çıkış Pinleri, Analog/Sayısal dönüştürücü, Seri/Paralel haberleşme portları, Zamanlayıcı (Timer) gibi birçok birimi içerisinde barındırmasıdır. Ayrıca mikrodenetleyiciler Program Hafizası (On-Chip Program Memory) sayesinde 
defalarca programlanabilir [6]. Mikrodenetleyiciler, tıp elektroniği [7], [8], güç elektroniği [9] ve yenilenebilir enerji alanlarında [10] sıklıkla kullanılmaktadır.

Günümüzde mikrodenetleyici üreten birçok firma mevcuttur (Microchip, Texas Instruments, Renesas, Atmel, v.b.). Üreticiler genel amaçlı, uygulamaya yönelik (Otomotiv, medikal cihaz veya motor sürücü devreleri) veya özel amaçlı (Sinyal işleme, ARM mimarisi kullanılan) mikrodenetleyicileri piyasaya sürmektedirler. Kullanıcı çözmek istediği probleme göre mikrodenetleyici özelliklerini göz önünde bulundurarak seçim yapmalıdır.

Entegre test devresinde Microchip firmasına ait PIC18F452 isimli mikrodenetleyici kullanılmıştır [11]. PIC18F452 32Kbyte program hafizasına, 1,5Kbyte data hafizasına sahiptir. Faz kilitli döngü (PLL) kullanılarak $40 \mathrm{MHz}$ çalışma saat frekansına çıkabilmektedir. 33 adet Giriş/Çıkış pinine, 10-bit Analog/Sayısal çeviriciye, 4 adet zamanlayıcıya (Timer) ve kullanıcının çevre birimleri ile haberleşmesini sağlayan donanımlara sahiptir. Birim fiyatının uygun olması, kolay ulaşılabilir olması, teknik destek ve uygulama alanlarının geniş olması ve diğer özelliklerinden dolayı belirtilen mikrodenetleyici çalışmada tercih edilmiştir.

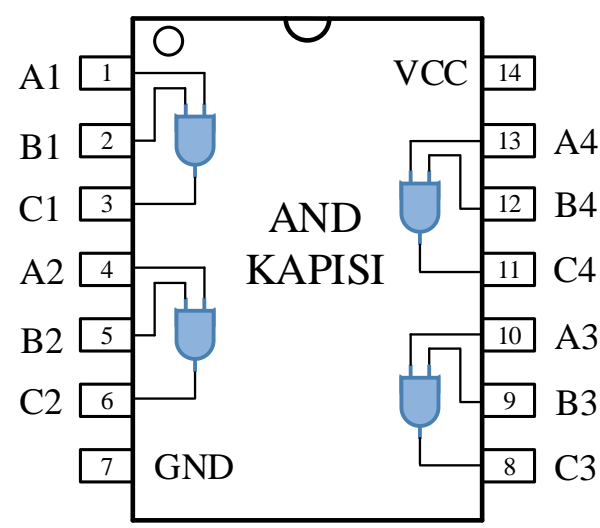

AND kapısı
doğruluk tablosu
\begin{tabular}{|c|c|c|}
\hline Girişler & Ç1kış \\
\hline A & B & C \\
\hline 0 & 0 & 0 \\
\hline 0 & 1 & 0 \\
\hline 1 & 0 & 0 \\
\hline 1 & 1 & 1 \\
\hline
\end{tabular}

Şekil 1. Lojik AND kapısının şematik gösterimi ve doğruluk tablosu

Entegre test devresinin şematik gösterimi ve baskı devre çizimi için KiCad yazılımı kullanılmıştır [12]. KiCad açık kaynak kodlu, internet üzerinden herkesin ulaşabileceği ve geniş kütüphanelere sahip profesyonel bir yazılımdır. Entegre test devresinin donanım bölümleri;

$\checkmark$ Güç katı

$\checkmark$ Kontrol k1smı (PIC18F452)

$\checkmark$ Gerilim ve toprak hattı yönlendirmesi

$\checkmark$ Gösterge paneli

Güç katı; Mikrodenetleyici, entegreler ve göstergenin çalışması için gerekli besleme gerilimini sağlamaktadır. Şekil 2'de devrenin güç katı görülmektedir.

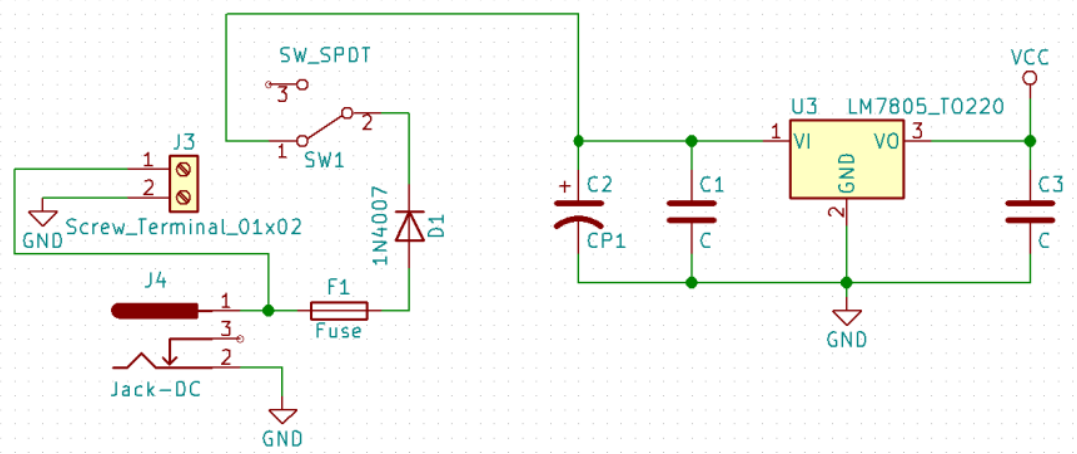

Şekil 2. Entegre test devresinin güç katı 
$\mathrm{J} 3$ ve J4 girişlerinden birine 9V veya 12V DC gerilim uygulanmaktadır. J3 iki girişli bask1 devre tipi klemenstir. J4 ise adaptörler için JACK bağlantısıdır. İki giriş yapılmasının sebebi adaptörün olmadığ 1 durumlarda J3 girişine kablo yardımıyla harici bir kaynaktan giriş yapılabilmesidir. F1 sigortası devreyi aşırı akımlardan korumak için konulmuştur $(0,5 \mathrm{~A})$. D1 diyotu J3 ve J4 girişlerine bağlanan DC gerilimin ters bağlanması durumunda oluşacak hasarlardan devreyi korumaktadır. 7805 elamanı PIC18F452, entegre ve gösterge paneli için gerekli DC 5V seviyesini elde etmek kullanılmıştır.

Kontrol kısmı; PIC18F452 mikrodenetleyicisinin entegre ile olan bağlantısı Şekil 3’te gösterilmiştir. Entegrelerin kolay bir şekilde devreye takılıp sökülmesi için 40 pin zif-soket kullanılmıştır (J1).
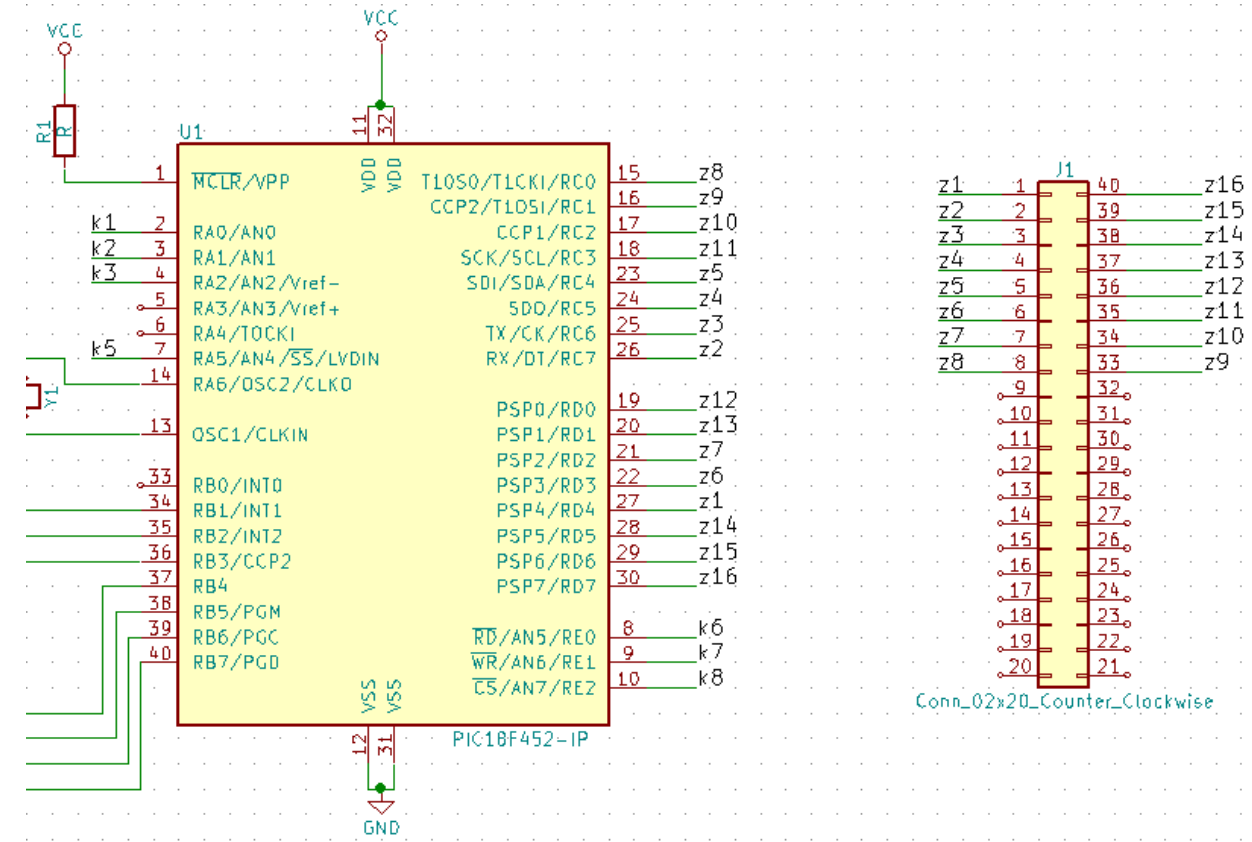

Şekil 3. Entegre test devresinin kontrol kısmı

Test devresi maksimum 16 pinli entegreleri test etmek için tasarlanmıştır. Entegrenin tüm pinlerine karşıllk mikrodenetleyicinin $\mathrm{C}$ ve $\mathrm{D}$ portları bağlanmıştır. $\mathrm{C}$ ve $\mathrm{D}$ portları yazılan programa göre giriş/çıkış olarak ayarlanabilmektedir. Farklı entegrelerin farklı giriş/çıkış kombinasyonlarına göre $\mathrm{C}$ ve $\mathrm{D}$ portlarının yazılan kod çerçevesinde esnek bir şekilde değiştirilmesi devrenin avantajı olarak karşımıza çıkmaktadır.

Gerilim ve toprak hattı yönlendirmesi; Entegreler aktif elemanlar olduğu için besleme gerilimi uygulanmalıdır. Şekil 1'deki AND kapısı incelendiğinde 7 ve 14 numaralı pinler sırasıyla GND(toprak) ve VCC'dir (DC 5V). Pratik olarak düşünüldüğünde mikrodenetleyicinin D7 pini çıkış olarak ayarlanır ve değeri lojik 1 yapılır $(\mathrm{VCC}=5 \mathrm{~V})$. D2 pini ise giriş olarak ayarlanarak entegrenin toprağı bağlanmış olur. Fakat mikrodenetleyicinin her bir pininin çekebileceği ve sağlayabileceği akım değeri vardır (sink/source). $\mathrm{Bu}$ değerlerden fazla akım uygulandığında mikrodenetleyici arızalanabilir. Bunun için 7805 çıkışından alınan $5 \mathrm{~V}$ entegreye ulaştırılmalıdır. Bir diğer problem ise farklı entegrelerin VCC ve GND pinlerinin yerleri değişik olabilir. 74LS73 entegresinin 4 numaralı pini VCC 11 numaralı pini ise GND' dir. Görüldüğü gibi giriş/çıkış, VCC ve GND pinlerinin değişik entegre tipleri için ayarlanması gerekir. VCC ve GND değerlerinin ilgili pine doğrudan bağlanması yerine transistörler kullanılarak kontrollü bir şekilde verilmesi sağlanabilir. Şekil 4'te VCC bağlantısının transistörler vasıtası ile ilgili entegreye aktarılması gösterilmiştir. Örneğin 4 numaralı pini VCC olan bir entegrede Q1 ve Q5 transistörlerinin girişine mikrodenetleyici tarafından lojik 0 uygulanırsa transistörler kesime gider. Transistörler kesime gidince z5 ve z16 bağlantılarına VCC gerilimi geçemez. Bu pinler entegre için giriş/çıkış olarak ayarlanabilir. Q3 numaralı transistöre lojik 1 uygulandığında ise Q3 ve Q4 iletime geçer. İletime geçen Q4 transistörü üzerinden VCC 4 numaralı pine aktarılır. 

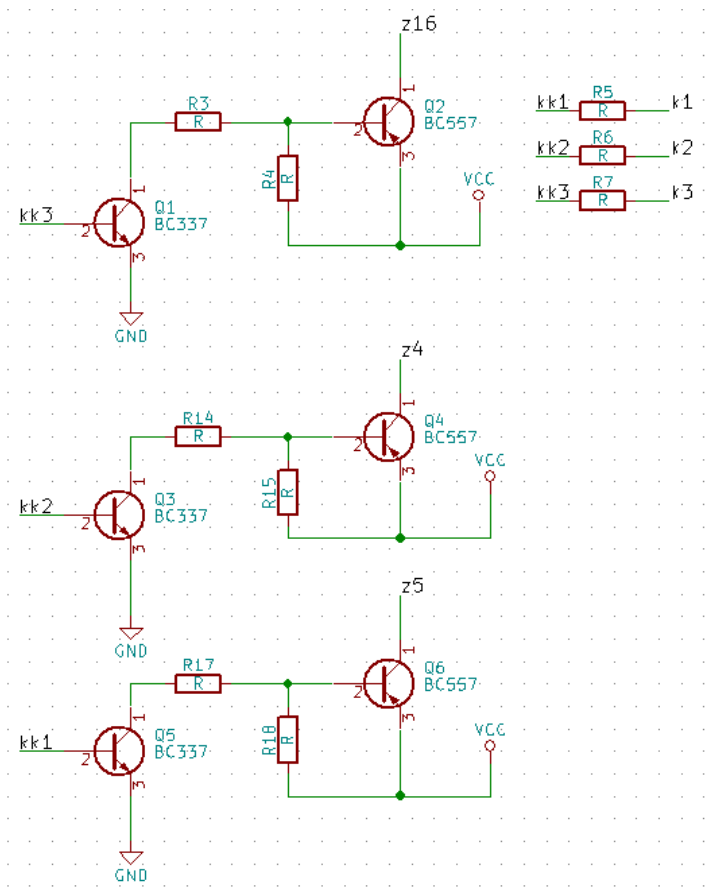

Şekil 4. Farklı pin dizilimine sahip entegrelerin VCC bağlantıları

Benzer şekilde GND bağlantıları transistörler vasıtasıyla yapılabilir. Şekilde 5'te ise farklı entegrelerin farklı yerlerindeki GND pinlerine transistörler aracılığı ile yapılan bağlantı gösterilmiştir.

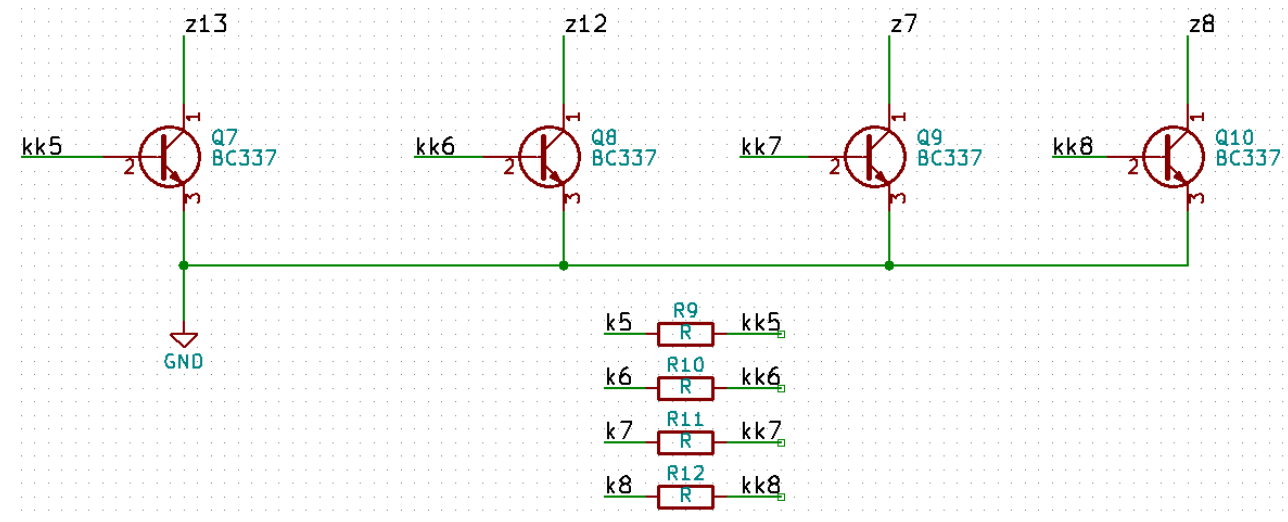

Şekil 5. Farklı pin dizilimine sahip entegrelerin GND bağlantıları

Örneğin 11 numaralı pini GND olan bir entegrede Q8, Q9, Q10 transistörlerinin girişleri lojik 0, Q7 transistörünün girişi lojik 1 yapılır. Q7 iletime geçtiği için test edilecek entegre içindeki akımlar transistör üzerinden geçerek toprak hattına ulaşır.

Gösterge paneli; Bu kısımda kullanıcıya bilgi verilmektedir. Gösterge olarak 2x16 alfa-nümerik Sıv1 Kristal Gösterge (LCD) kullanılmıştır. Şekil 6'da mikrodenetleyici ve LCD arasındaki bağlantı gösterilmiştir. 


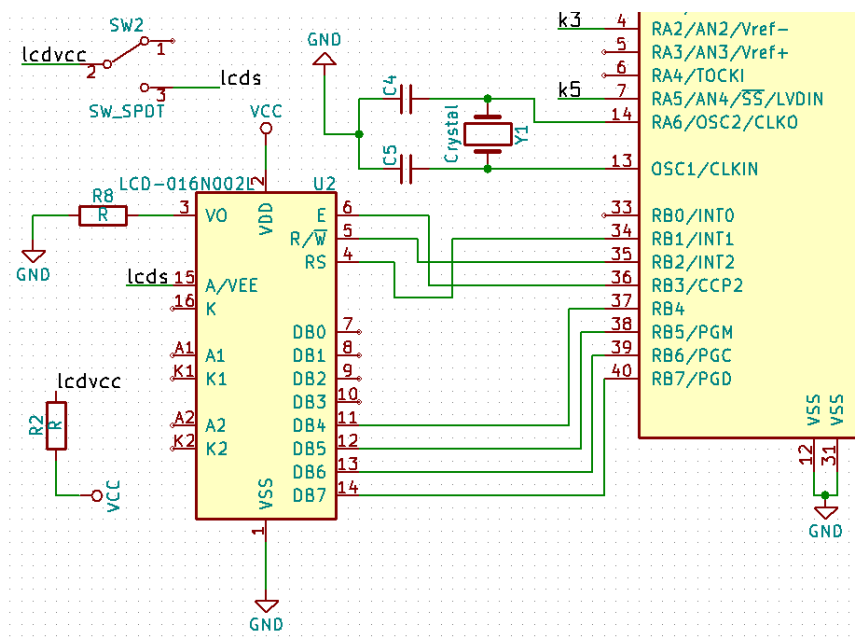

Şekil 6. LCD ile mikrodenetleyicinin bağlantı şeması.

Devrenin şematik tasarımı yapıldıktan sonra baskı devre (PCB) çizimine geçilmiştir. KiCad programında şematik olarak çizilen devrenin "Netlist" dosyası oluşturulur. KiCad PCB dosyası açılarak Netlist dosyası okutulur. Şematikten eklenen elemanların PCB çizimi yapılır. Şekil 7'de tasarlanan devrenin PCB çizimi ve 3 boyutlu görseli verilmiştir.

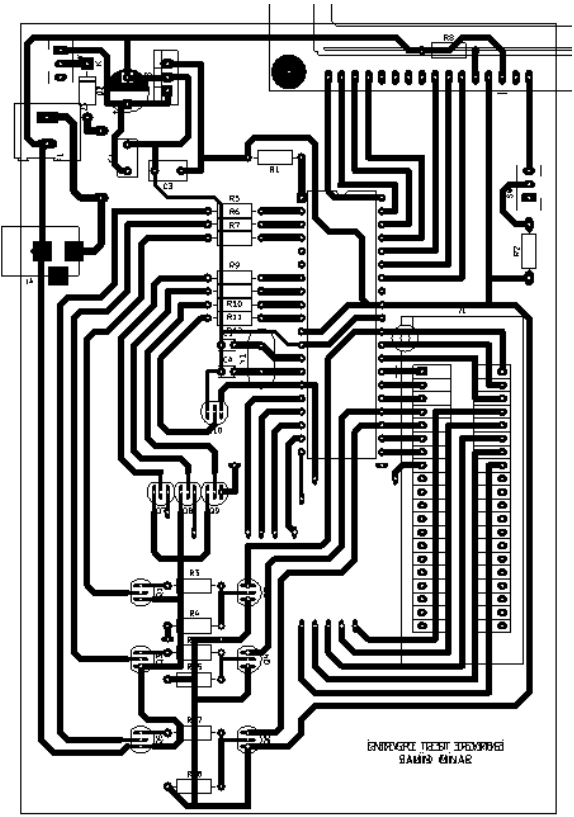

(a)

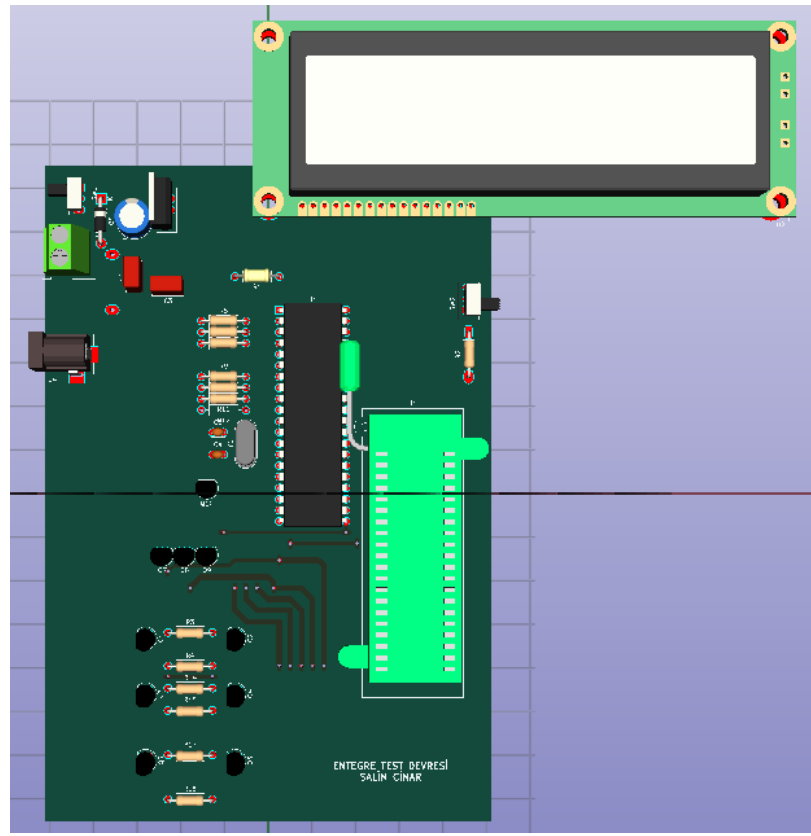

(b)

Şekil 7. Entegre test devresinin (a) PCB çizimi (b) 3 boyutlu gösterimi.

Entegre test devresi kullanıcı kolaylığı göz önünde tutularak tasarlanmıştır. Devreye enerji verildikten sonra test etme işlemine hemen geçilmektedir. Test edilecek entegrenin 1 numaralı bacağ 1 zif-soketin 1 numaralı bacağına gelecek şekilde takılmalıdır. Mikrodenetleyici yazılan program sayesinde gerekli tüm pin ayarlamalarını yaparak test işlemine geçer ve sonucu LCD ekranında gösterir.

\subsection{Entegre test devresi yazılım tasarımı}

Mikrodenetleyiciler kullanıcının yazdığı programa göre işlevlerini yerine getirmektedir. Yapılan çalışmada Microchip firmasına ait "MPLAB X-IDE" platformu kullanılmıştır [13]. MPLAB X-IDE, Microchip 
mikrodenetleyiciler ve dijital sinyal denetleyicileri için uygulamalar geliştirmek üzere bilgisayar üzerinde çalışan bir yazılımdır. Entegre Geliştirme Ortamı (IDE) mikrodenetleyicilerde kullanılacak kodları geliştirmek için gerekli bir ortam olarak düşünülebilir. IDE ortamında kod yazılabilir, yazılan kodların hata ayıklaması (Debug) yapılabilir. Yazılan kod IDE ortamında derlenerek mikrodenetleyiciye yüklenecek HEX dosyası oluşturulabilir. Ayrıca oluşturulan HEX dosyası uygun bir programlayıcı yardımıyla IDE yazılımı üzerinden mikrodenetleyiciye yüklenebilir. IDE ortamında Assembly dili veya C dili ile kod yazılabilir. PIC18F452 mikrodenetleyicisi C derleyicisine göre optimize edilmiş mimari/komut setine sahiptir. Bu yüzden kodlama için $\mathrm{C}$ dili tercih edilmiştir. $\mathrm{C}$ ile yazılan kodun derlenmesi için Microchip firmasına ait "XC8" derleyicisi kullanılmıştır. Şekil 8'de programın akış şeması gösterilmiştir.

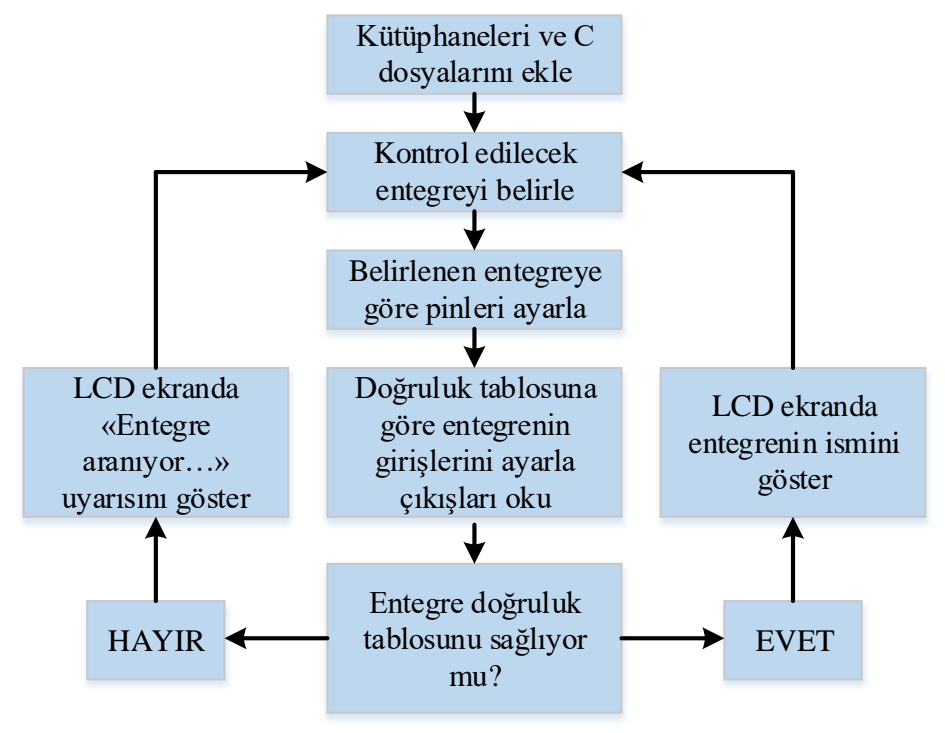

Şekil 8. Mikrodenetleyici için yazılan programın akış şeması.

Yazılan kod sürekli bir döngü içerisinde çalışmaktadır. İlk olarak gerekli kütüphaneler ve C dosyaları programa dâhil edilir. Mikrodenetleyicinin çalışması için gerekli konfigürasyon ayarları yapılır. Ayarlamalar bittikten sonra test işlemine geçilir. Test edilecek entegreler önceden belirlenmiştir. Yapılan çalışmada Lojik devre laboratuvarlarında sıklıkla kullanılan entegreler seçilmiştir. Tablo 1'de tasarlanan devrenin test edebileceği entegreler verilmiştir. Bu sayı ihtiyaca göre artırılabilir. Test edilecek entegre zifsokete takılır. Takılan entegre ile Tablo 1'deki entegreler sırasıyla tek tek karşılaştırılır. Örnek bir karşılaştırma işlemi aşağıda verilmiştir.

1. Tablo 1.'deki ilk entegre seçilir. Burada 74LS00 verilmiştir. (Sıralama istenirse değişebilir)

2. Entegrenin VCC ve GND pinleri aktif hale getirilir. Entegrenin giriş/çıkış pin konfigürasyonuna göre PIC18F452 mikrodenetleyicisinin pinleri ayarlanır.

3. Seçilen entegrenin doğruluk tablosundaki girişlerine karşılık çıkışları incelenir.

4. Eğer doğruluk tablosunun tamamı sağlanmamışsa LCD ekranına "Entegre aranıyor..." yazdır. Eğer doğruluk tablosunun tamamı sağlanmışsa LCD ekranına entegrenin ismini yazdır (Örneğin “74LS00 NAND”). Tablo 1'de verilen bir sonraki entegreyi seç. Adım 2'ye tekrardan git.

Test etme işlemi enerji olduğu sürece devam etmektedir. 
Tablo 1. Test devresinin test edebildiği entegreler.

\begin{tabular}{|l|l|}
\hline 14 Bacaklılar (gnd:7, vcc=14) & 16 Bacaklılar (gnd:8, vcc:16) \\
\hline 1) 74LS00 (NAND) & 15) 74LS138 (3x8 Decoder) \\
\hline 2) 74LS02 (NOR) & 16) 74LS139 (2x8 Decoder) \\
\hline 3) 74LS04 (NOT) & 17) 74LS148 (8x3 Encoder) \\
\hline 4) 74LS08 (AND) & 18) 74LS151 (1x8 Mux) \\
\hline 5) 74LS32 (OR) & 19) 74LS153 (1x4 Mux) \\
\hline 6) 74LS86 (EXOR) & 20) 74LS155 (2x4 Decoder) \\
\hline 7) 74LS74 (D flip flop) & 21) 74LS157 (4 bit 2x1 Mux) \\
\hline 8) 74LS164 (8 bit shift register) & 22) 74LS165 (8 bit PISO SR) \\
\hline 9) 74LS20 (4 input nand) & 23) 74LS174 (D flip flop with clear) \\
\hline 10) 74LS21 (4 input and) & 24) 74LS194 (4 bit Bidirectional SR) \\
\hline 11) 4077 (EXNOR) & 25) 74LS83 (gnd:12, vcc:5) (4 bit \\
& Binary adder) \\
\hline 12) 74LS73 (gnd:11, vcc:4)(JK FF) & 26) 74LS75 (gnd:12, vcc:5) (Quad latch) \\
\hline 13) 74LS90 (gnd:10, vcc:5) (Binary counter) & 27) 74LS76 (gnd:13, vcc:5) (JK FF) \\
\hline 14) 74LS93 (gnd:10, vcc:5) (4 bit Binary counter) & 28) 74LS283 (4 bit Binary FA) \\
\hline & 29) CD4011 (NAND) \\
\hline
\end{tabular}

\section{GERÇEK ZAMANLI DENEMELER (REAL TIME TRIALS)}

Tasarlanan entegre test devresinin prototipi ürün haline getirilip denenmiştir. Devre eğitim öğretim döneminde Lojik devre laboratuvarında kullanılmıştır. Şekil 9'da ürün haline getirilen test devresinin çeşitli uygulamaları görülmektedir.

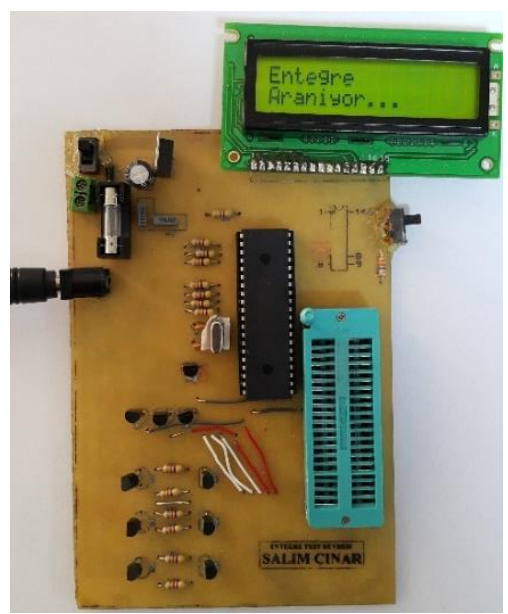

(a)

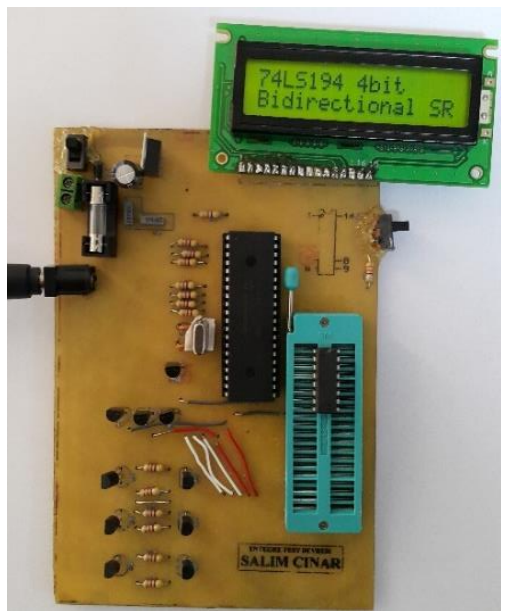

(b) 


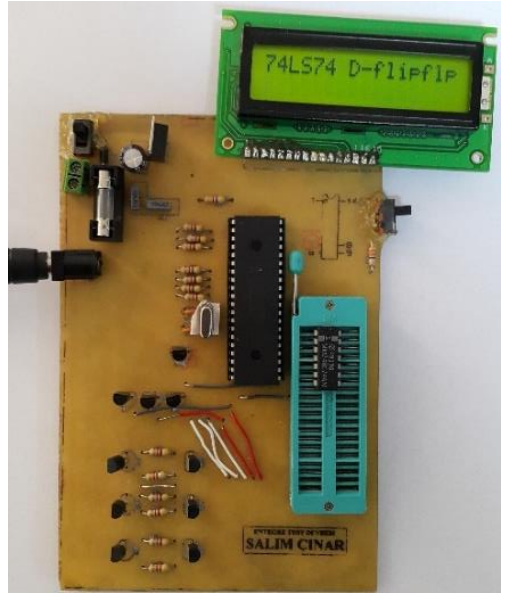

(c)

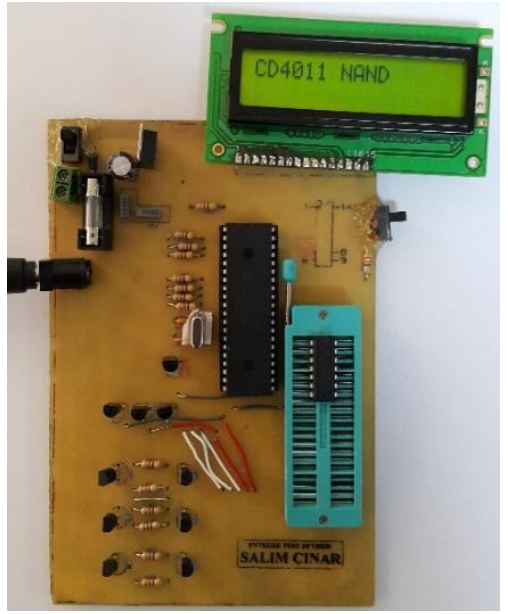

(d)

Şekil 9. Entegre test devresinin gerçek zamanlı çalışması. (a) Entegre olmadĭ̆ı veya bozuk olduğu durum. (b)(c)(d) Sağlam entegrenin LCD ekraninda gösterilmiş durumu.

Yapılan denemelerde test devresinin sorunsuz bir şekilde çalıştı̆̆ görülmüştür. Devre entegreleri çok hızlı bir şekilde kontrol edebilmektedir. Laboratuvarda görevli kişilerin test işlemi için harcayacağ 1 zaman büyük ölçüde düşmektedir. Bazı entegrelerde aynı lojik yapı birden fazla olabilir. Şekil 1'de gösterildiği gibi bir entegrede 4 adet AND kapısı mevcuttur. Fiziki olarak bu kapılardan bir tanesi veya birkaç tanesi arızalı olup geri kalanı çalışabilir. Test devresi bu kapıların hepsini tek tek kontrol etmektedir. Test devresi arızalı veya sağlam olarak sınıflama yapıp LCD ekranda gösterebilir. Düşünce olarak sağlam kapı elemanları kullanılabilir. Fakat entegrelerin işaretlenmesi ve bir sonraki deneylerde kullanılması sırasında bu durumun dikkate alınması gerekmektedir. Pratik olarak bunun yapılması zordur ve kullanıcının hata yapma ihtimali artmaktadır. Bu nedenle entegrenin içinde bulunan lojik yapıların hepsinin sağlam olması gerekmektedir. Test devresinin yazılımı belirtilen koşullara göre yapılmıştır.

\section{SONUÇ (CONCLUSION)}

Mühendislik eğitiminde laboratuvarlar önemli bir yer tutmaktadır. Laboratuvarlarda kullanılacak malzemelerin sağlamlığının deneylerin öncesinde ve sonrasında kontrol edilmesi gerekmektedir. Yapılan çalışmada Elektrik-Elektronik Mühendisliğinde bulunan Lojik devre laboratuvarı için entegre test devresi tasarlanmıştır. Test devresinin kullanımı kolay olacak şekilde tasarım yapılmıştır. Devre tak-çalıştır özelliğine sahiptir. Kullanıcının harici olarak bir ayar yapmasına gerek yoktur. Devreye enerji verildikten sonra test edilecek entegre zif-sokete yerleştirilir. PIC18F452 mikrodenetleyicisi kontrol işlemini başlatır. Eğer entegre içindeki lojik yapılar doğruluk tablosunu sağlıyorsa LCD ekrana entegrenin adı yazdırılır. Tasarlanan devrenin avantajları şu şekilde sıralanabilir. Entegreler hızlı ve doğru test edilebilmektedir. Böylelikle zamandan tasarruf yapılmaktadır. Üzeri silinmiş veya okunmayan entegreler test cihazı sayesinde belirlenebilir. Entegre test devresi bu hali ile mevcut ihtiyaçları karşılamakta ve sorunsuz çalışmaktadır. Devre tasarımı gelişime açıktır. İleriki dönem çalışmalarında daha kapsamlı ve akıllı tasarımların yapılması planlanmaktadır. Örneğin hafıza birimi konularak daha fazla entegrenin test edilmesi sağlanabilir. Bilgisayar destekli bir yapı oluşturulabilir. Bilgisayar için tasarlanan bir arayüz ile farklı entegre tipleri için test döngüsü yapılabilir. Yapılan çalışma ile tasarlanan devrenin Lojik devre laboratuvarları için faydalı olacağı düşünülmektedir. 


\section{KAYNAKLAR (REFERENCES)}

[1] A. Akgül, M. K. Uçar, M. M. Öztürk, ve Z. Ekşi, "Mühendislik Eğitiminin İyileştirilmesine Yönelik Öneriler, Geleceğin Mühendisleri ve İşgücü Analizi”, Süleyman Demirel Üniversitesi Fen Bilim. Enstitüsü Derg., c. 17, sy 1, 2013.

[2] E. Can, "Laboratuvar Çalışmalarının Bilgisayar Mühendisliği Eğitimindeki Yeri ve Önemi”, Elektr. MÜHENDISLI ĬG $\dot{I}$, sy 430, ss. 94-96, 2007.

[3] C. S. Lee, J. H. Su, K. E. Lin, J. H. Chang, ve G. H. Lin, “A Project-Based Laboratory for Learning Embedded System Design With Industry Support”, IEEE Trans. Educ., c. 53, sy 2, ss. 173-181, May. 2010.

[4] L. A. Ajao, J. Agajo, J. G. Kolo, M. A. Adegboye, ve Y. Yusuf, "Learning of Embedded System Design, Simulation and Implementation: A Technical Approach", Am. J. Embed. Syst. Appl., c. 3, sy 3, s. 35, May. 2016.

[5] M. Özcan ve H. Günay, "Mikrodenetleyici geliştirme seti tasarım ve uygulamaları", Design and applications development kit microcontroller, 2009.

[6] B. Korol, "PIC Mikrodenetleykiler ve Program Geliştirme Kartı Uygulaması", Sak. Univ. J. Sci., c. 7, sy 3, ss. 179-184, Eyl. 2003.

[7] M. E. Aktan, İ. Göker, E. Akdoğan, ve B. Öztürk, "Design, implementation and performance analysis of a microcontroller based wireless electromyography device", içinde 2017 Medical Technologies National Congress (TIPTEKNO), 2017, ss. 1-4.

[8] S. C. Yener ve R. Mutlu, "A microcontroller-based ECG signal generator design utilizing microcontroller PWM output and experimental ECG data", içinde 2018 Electric Electronics, Computer Science, Biomedical Engineerings' Meeting (EBBT), 2018, ss. 1-4.

[9] R. Bayindir, I. Colak, E. Kabalci, ve A. Gorgun, "PID controlled synchronous motor for power factor correction", içinde 2009 International Conference on Power Engineering, Energy and Electrical Drives, 2009, ss. 408-412.

[10] M. Demirtas, I. Sefa, E. Irmak, ve I. Colak, "Low-cost and high sensitive microcontroller based data acquisition system for renewable energy sources", içinde Automation and Motion 2008 International Symposium on Power Electronics, Electrical Drives, 2008, ss. 196-199.

[11] "PIC18F452 - Microcontrollers and Processors - Microcontrollers and Processors", 23-Tem-2018. [Çevrimiçi]. Erişim adresi: https://www.microchip.com/wwwproducts/en/PIC18F452. [Erişim: 23Tem-2018].

[12] "KiCad EDA". [Çevrimiçi]. Erişim adresi: http://kicad-pcb.org/. [Erişim: 25-Tem-2018].

[13] "MPLAB- X IDE | Microchip Technology". [Çevrimiçi]. Erişim adresi: http://www.microchip.com/mplab/mplab-x-ide. [Erişim: 26-Tem-2018]. 